\title{
Analisis Konduktivitas Termal Endapan Sinter di Kabupaten Solok dan Solok Selatan
}

\author{
Rahmat Ilham*, Ardian Putra \\ Laboratorium Fisika Bumi, Jurusan Fisika \\ Fakultas Matematika dan Ilmu Pengetahuan Alam Universitas Andalas \\ Kampus Unand LimauManis, Padang, 25163 Indonesia \\ *rahmatilham866@gmail.com
}

\begin{abstract}
ABSTRAK
Penelitian ini bertujuan untuk menganalisis konduktivitas termal endapan sinter yang terdapat di sekitar mata air panas Garara dan Cupak, Kabupaten Solok, dan Sapan Maluluang, Kabupaten Solok Selatan. Perbedaan utama dari kedua endapan sinter di masing-masing lokasi adalah daerah Sapan Maluluang memiliki kandungan sinter silika murni, sedangkan daerah Garara dan Cupak memiliki kandungan sinter silika dan karbonat dengan persentase yang berbeda. Penelitian ini dimulai dengan perancangan alat konduktivitas termal. Pengujian konduktivitas termal endapan sinter menggunakan metode Trancient Divided Bar (TDB), dan diuji pada suhu rata-rata yaitu $25,7^{\circ} \mathrm{C}$. Titik pengambilan sampel terdiri dari dua titik di mata air panas Garara, tiga titik di mata air panas Cupak serta satu titik di mata air panas Sapan Maluluang. Nilai konduktivitas termal rata-rata sumber air panas di Garara dan Cupak adalah 21,75 $\mathrm{W} / \mathrm{m}^{\circ} \mathrm{C}$, sedangkan nilai rata-rata konduktivitas termal sumber air panas di Sapan Maluluang adalah $26,49 \mathrm{~W} / \mathrm{m}^{\circ} \mathrm{C}$. Tingginya kandungan silika akan menghasilkan nilai konduktivitas termal yang lebih tinggi.
\end{abstract}

Kata Kunci: konduktivitas termal, mata air panas, mineral karbonat, mineral silika, tracient divided bar

\begin{abstract}
This study aims to analyze the thermal conductivity of sinter deposits found around Garara and Cupak hot spring, Solok Regency, and Sapan Maluluang hot springs, Solok Selatan Regency. The main difference between the two sinter deposits in each location is that the Sapan Maluluang area has a pure sinter content of silica, while the Garara and Cupak regions have sinter content of silica and carbonate with different percentages. This study begins with the design of a thermal conductivity tool. Thermal conductivity test is examined using Trancient Divided Bar (TDB) method. The test is carried out at a temperature of about $25,7^{\circ} \mathrm{C}$. Two samples from Garara, three samples from Cupak, and one sample from Sapan Maluluang are prepared for thermal conductiviy test. The average thermal conductivity of sinter deposit in Garara and Cupak is $21.75 \mathrm{~W} / \mathrm{m}^{\circ} \mathrm{C}$, while the average thermal conductivity of silica sinter in Sapan Maluluang is $26.49 \mathrm{~W} / \mathrm{m}^{\circ} \mathrm{C}$. The high silica content will result in higher thermal conductivity values.
\end{abstract}

Keywords: thermal conductivity, hot springs, carbonate minerals, silica minerals, tracient divided bar

\section{PENDAHULUAN}

Sumatera Barat memiliki potensi panas bumi dengan total sumber daya mencapai 1656 Megawatt (MW) (Departemen Energi dan Sumber Daya Mineral, 2012). Potensi ini tersebar pada 16 titik di 7 kabupaten, terutama terdapat di Kabupaten Solok dan Solok Selatan yang ditandai dengan munculnya sumber mata air panas. Mata air panas merupakan salah satu manifestasi panas bumi yang muncul ke permukaan dalam bentuk fluida dan ditandai dengan adanya endapan sinter (Saptadji, 2009).

Endapan sinter merupakan batuan sedimen yang terbentuk dari proses alterasi mineral pada sistem geotermal di sekitar mata air panas. Pembentukan sinter dikontrol oleh konsentrasi mineral yang berada di reservoir panas bumi. Keadaan tersebut menyebabkan terjadinya perbedaan tipe mata air panas. Berdasarkan tipe mata air panas, endapan sinter terbagi atas sinter silika dan sinter karbonat. Endapan sinter digunakan sebagai indikator suhu bawah reservoir, dimana endapan sinter silika mengindikasikan reservoir bersuhu tinggi yang bernilai $150-240^{\circ} \mathrm{C}$, sedangkan endapan sinter karbonat mengindikasikan reservoir bersuhu sedang yang bernilai $90-150^{\circ} \mathrm{C}$ (Wohletz dan Heiken, 1992).

Penelitian tentang tipe mata air panas pernah dilakukan oleh Burhan dan Putra (2017) diseluruh mata air panas di Sumatera Barat. Mata air panas Sapan Maluluang di Solok Selatan bertipe alkali klorida yang memiliki endapan sinter silika, sedangkan mata air panas Garara dan 
Cupak di Kabupaten Solok bertipe bikarbonat yang bisa memiliki endapan sinter yaitu campuran antara silika dengan karbonat. Inanda dan Putra (2017) juga pernah melakukan penelitian tentang endapan sinter yang berasal dari mata air panas di Sapan Malulung Kabupaten Solok Selatan dan di Garara, Bawah Kubang Kabuapaten Solok menggunakan XRD (X-Ray Diffractometer). Hasil penelitian menunjukkan bahwa endapan sinter silika terdapat pada mata air panas Sapan Maluluang, dan Garara, sedangkan pada mata air panas Bawah Kubang memiliki endapan sinter karbonat. Mata air panas yang bertipe alkali klorida memiliki potensi panas bumi yang lebih baik dari pada mata air panas yang bertipe bikarbonat (Saptadji, 2009).

Setiap endapan sinter memiliki sifat termal, salah satunya yaitu konduktivitas termal. Nilai konduktivitas termal batuan dapat dimanfaatkan untuk mengetahui potensi reservoir sumber panas bumi. Konduktivitas termal batuan mengindikasikan seberapa cepat panas dalam reservoir mengalir sampai ke permukaan bumi (Saptadji, 2009). Beberapa cara yang digunakan untuk mengetahui konduktivitas termal batuan yaitu menggunakan metode needle probe yang merupakan alat yang telah dikembangkan secara digital dengan melakukan pengukuran langsung di lapangan. Selain itu, juga telah banyak dikembangkan beberapa metode pengukuran konduktivitas termal seperti menggunakan metode Modified Transient Plane Source (MTPS) dan metode Tracient Divided Bar (TDB) (Pasquale dkk., 2015). Prinsip metode TDB adalah sebuah bahan yang memiliki perbedaan temperatur antara dinding sebelah kiri $\left(T_{1}\right)$ dengan dinding sebelah kanan $\left(T_{2}\right)$ dimana $T_{1}$ lebih besar dari $T_{2}$, sehingga akan ada terjadi perpindahan panas dari $T_{1}$ ke $T_{2}$ berjarak L dari tebal bahan (Pasquale dkk., 2015). Kelebihan metode ini adalah memiliki skema rangkaian yang mudah, biaya yang murah, dan tenaga kerja yang dibutuhkan sedikit.

Velez dkk. (2017) melakukan penelitian tentang pengujian konduktivitas termal batuan di sekitar mata air panas di Los Nevados Columbia menggunakan needle probe. Nilai konduktivitas termal yang didapatkan berkisar 1,81-2,98 W/m. ${ }^{\circ} \mathrm{C}$. Nilai konduktivitas termal ini dapat mengestimasi temperatur dan kedalaman reservoir pada daerah panas bumi. Velez dkk. (2017) melakukan pemodelan 3D model geologi sehingga didapatkan perkiraan nilai maksimum temperatur reservoir yang didapatkan sekitar $532{ }^{\circ} \mathrm{C}$ dengan kedalaman $2-3 \mathrm{~km}$.

Sipio dkk. (2013) melakukan pengujian konduktivitas termal batuan yang terdapat di sekitar daerah geotermal di Italia yaitu di daerah Puglia, Calabria, Campania, dan Sicily menggunakan metode Modified Transient Plane Source (MTPS) dengan jumlah sampel batuan yang berjumlah 77 . Nilai konduktivitas termal yang didapatkan ada 2 yaitu nilai konduktivitas termal batuan dalam keadaan kering $\left(\lambda_{d r y}\right)$ dan nilai konduktivitas termal batuan dalam keadaan basah $\left(\lambda_{\text {wet }}\right)$. Nilai konduktivitas termal kering $\left(\lambda_{d r y}\right)$ yang didapatkan berkisar antara $0,4-3,5$ $\mathrm{W} / \mathrm{m} .{ }^{\circ} \mathrm{C}$ dan nilai kondukitivitas basah $\left(\lambda_{\text {wet }}\right)$ didapatkan berkisar $1,3-3,9 \mathrm{~W} / \mathrm{m} .{ }^{\circ} \mathrm{C}$. Perbedaan nilai konduktivitas ini disebabkan karena perbedaan tipe batuan yang terdapat di sekitar daerah geotermal. Kelemahan dari metode MTPS ini adalah membutuhkan biaya yang mahal, sampel yang banyak, dan di Indonesia belum ada yang menggunakan metode ini. Endhovani dan Putra (2016) telah melakukan penelitian tentang konduktivitas termal endapan sinter silika di Sapan Maluluang Kabupaten Solok Selatan menggunakan metode TDB, tetapi didapatkan nilai ratarata konduktivitas termal sinter silika yang sangat tinggi yaitu sebesar $1170,37 \mathrm{~W} / \mathrm{m}^{\circ} \mathrm{C}$. Nilai yang sangat tinggi tersebut diduga karena banyaknya panas yang hilang pada saat pengukuran konduktivitas termal dan melebihi nilai literatur yang ada.

Oleh karena itu, pada penelitian ini dilakukan perbaikan rancangan alat pengukur konduktivitas termal berdasarkan ASTM (American Standard Testing Material) E1225-87 untuk sampel endapan sinter yang berasal dari mata air panas Sapan Maluluang di Kabupaten Solok Selatan, Cupak dan Garara di Kabupaten Solok.

\section{METODE}

\subsection{Pengambilan Sampel}

Pada tahap ini dilakukan pengambilan sampel endapan sinter pada enam titik daerah sumber mata air panas dan diberi label angka (1-6). Satu titik berada pada daerah Sapan Maluluang Kabupaten Solok Selatan (1), dua titik berada pada daerah Garara (2,3) dan tiga titik 
berada pada daerah Cupak Kabupaten Solok $(4,5,6)$. Teknik pengambilan sampel pada tiap lokasi sama dengan lokasi lainnya, sampel di ambil secara radial membentuk lingkaran di sekitar tepi sumber mata air panas. Pada setiap titik akan diambil tiga sampel tiap pengujian dan diberi label huruf (A-C). Lokasi pengambilan sampel dapat dilihat pada Gambar 1.

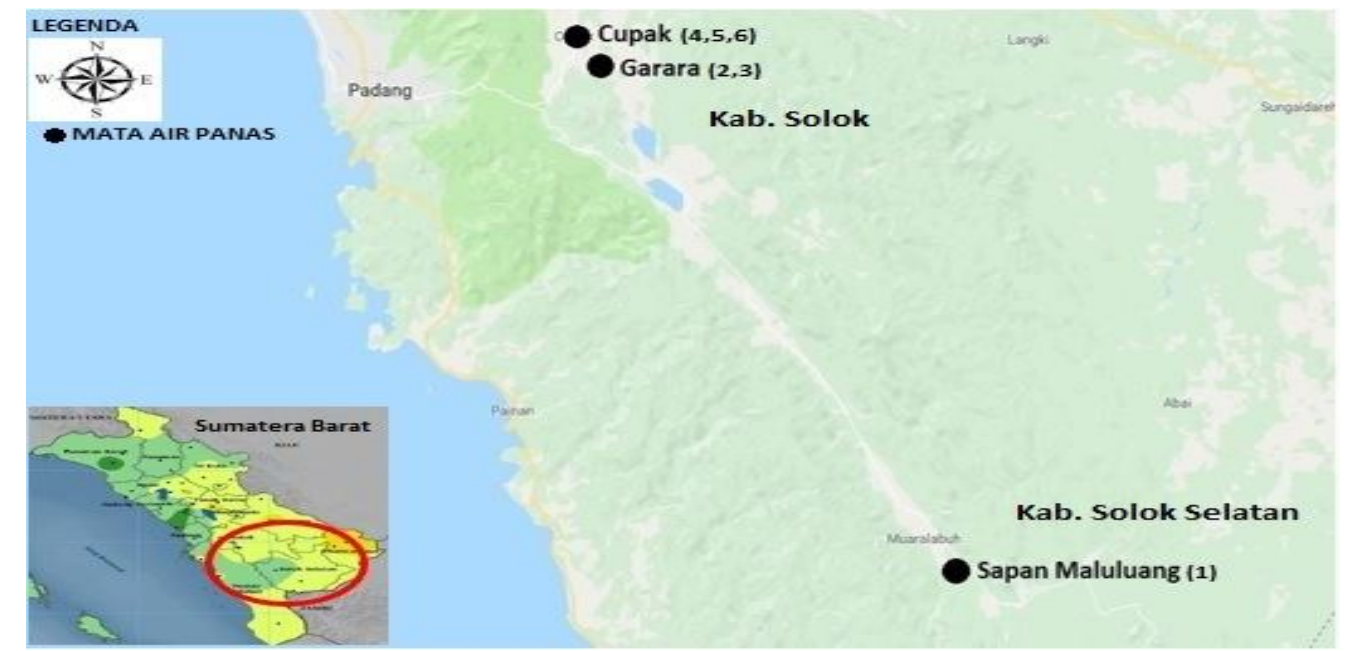

Gambar 1 Lokasi pengambilan sampel

\subsection{Perancangan Alat}

Pada tahap ini dilakukan perancangan alat dengan cara menyiapkan peralatan seperti bejana, plat besi, akrilik, termometer digital. Perancangan alat konduktivitas termal ini mengikuti aturan ASTM E1225-87 (Divided Bar Method), Standard Test Method For Thermal Conductivity of Solid. Langkah pertama yang dilakukan adalah membuat kotak sampel dari akrilik yang berukuran $15 \times 10 \times 5 \mathrm{~cm}^{3}$, kemudian plat besi dipotong berukuran 20 x $15 \mathrm{~cm}$. Alat konduktivitas termal ini disusun berdasarkan skema rangkaian yang dapat dilihat pada Gambar 2. Kekurangan alat ini adalah pengukuran konduktivitas termal yang membutuhkan waktu yang lama yaitu sekitar 1 jam untuk 1 sampel.

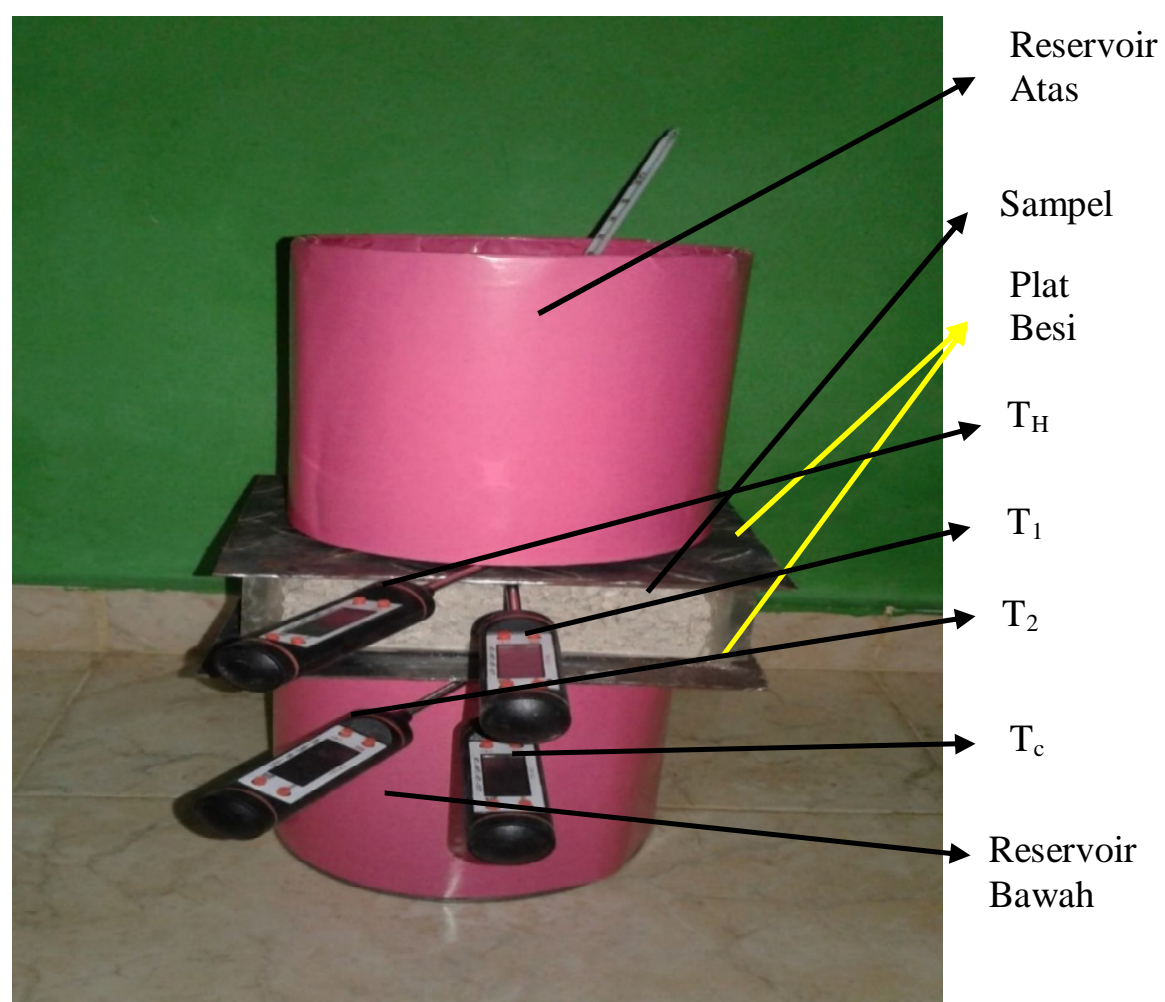

Gambar 2 Skema rangkaian alat uji konduktivitas termal 


\subsection{Pembuatan Sampel}

Pada tahap ini dilakukan pembuatan sampel dengan cara memasukan sampel ke kotak sampel dan jika terdapat rongga maka diisi dengan sampel endapan sinter yang halus.

\subsection{Uji Konduktivitas Termal}

Pada tahap ini dilakukan uji konduktivitas termal dengan cara sampel sinter silika berbentuk pasir dipadatkan dalam kotak sampel. Nilai konduktivitas panas besi atau plat besi penghubung $\left(\lambda_{r}\right)$ adalah $45,3 \mathrm{~W} / \mathrm{m}^{\circ} \mathrm{C}$. Reservoir bawah diisi dengan air dingin dan reservoir atas diisi dengan air panas. Pada reservoir atas, dipasang heater (pemanas) untuk memanaskan air hingga mencapai titik didih. Menunggu keadaan tunak (steady state), yaitu saat temperatur reservoir menunjukkan angka $98-99{ }^{\circ} \mathrm{C}$ konstan selama 10 menit. Pada menit ke sebelas, temperatur pada masing-masing termometer dicatat, dengan urutan $T_{H}, T_{l}, T_{2}, T_{c}$ selama 30 menit berikutnya dan dicatat setiap 1 menit sekali. Dihitung nilai rata-rata dari $T_{H}, T_{1}, T_{2}$, dan $T_{c}$. Selanjutnya nilai konduktivitas panas dihitung menggunakan Persamaan (1) .

$$
\lambda_{s}=\lambda_{r} \frac{\left(\Delta T_{a}+\Delta T_{b}\right)}{2 \Delta T_{s}}
$$

dengan $\lambda_{g}$ adalah konduktivitas panas batuan $\left(\mathrm{W} / \mathrm{m}^{\circ} \mathrm{C}\right), \lambda_{\mathrm{r}}$ adalah konduktivitas panas plat besi $\left(45,3 \mathrm{~W} / \mathrm{m}^{\circ} \mathrm{C}\right), T_{H}$ adalah temperatur antara reservoir panas dan logam atas $\left({ }^{\circ} \mathrm{C}\right), T_{l}$ adalah temperatur antara logam atas dan sampel batuan $\left({ }^{\circ} \mathrm{C}\right), T_{2}$ adalah temperatur antara sampel batuan dan logam bawah $\left({ }^{\circ} \mathrm{C}\right), T_{c}$ adalah temperatur antara logam bawah dan reservoir bawah $\left({ }^{\circ} \mathrm{C}\right) . \Delta T_{a}$ adalah selisih antara $T_{H}$ dengan $T_{l}, \Delta T_{b}$ adalah selisih antara $T_{2}$ dengan $T_{c}$, dan $\Delta T_{s}$ adalah selisih $T_{1}$ dengan $T_{2}$.

\section{HASIL DAN DISKUSI}

\subsection{Uji Konduktivitas Termal Endapan Sinter Silika di Kabupaten Solok Selatan}

Nilai konduktivitas termal endapan sinter silika di mata air panas Sapan Maluluang, Kabupaten Solok Selatan memiliki nilai rata-rata sebesar $26,49 \mathrm{~W} / \mathrm{m}^{\circ} \mathrm{C}$. Nilai rata-rata konduktivitas termal sinter silika tiap titik dapat dilihat pada Tabel 1.

Tabel 1 Nilai rata-rata konduktivitas termal sinter silika tiap titik

\begin{tabular}{ccccc}
\hline No & Lokasi & Sampel & $\boldsymbol{\lambda}\left(\mathbf{W} / \mathbf{m} .{ }^{\mathbf{0}} \mathbf{C}\right)$ & Rata-Rata $\left(\mathbf{W} / \mathbf{m} .{ }^{\mathbf{0}} \mathbf{C}\right)$ \\
\hline 1 & & 1A & 29,90 & \\
2 & Sapan Maluluang & 1B & 21,25 & 26,49 \\
3 & & 1C & 28,31 & \\
\hline
\end{tabular}

Berdasarkan Tabel 1, didapatkan nilai konduktivitas termal dari ketiga titik pengambilan sampel endapan sinter silika yang tidak jauh berbeda, terutama terdapat pada titik 1A dan 1C. Hal ini mengindikasikan bahwa ketiga sampel endapan sinter silika yang diambil di setiap lokasi penelitian berasal dari satu sumber yang sama. Parameter lain yang menyatakan bahwa endapan sinter silika berasal dari satu sumber yang sama adalah nilai resistivitas listrik endapan sinter. Nugroho dan Putra (2015) mendapatkan bahwa nilai resistivitas listrik endapan sinter silika di mata air panas Sapan Maluluang dari titik terdekat sampai terjauh memiliki nilai yang tidak jauh berbeda. Endapan sinter yang berasal dari satu sumber akan memiliki jenis dan jumlah kandungan mineral yang sama, sehingga besaran fisis yang dihasilkannya juga tidak jauh berbeda. Menurut Rachmawati (2013), menyatakan bahwa nilai konduktivitas panas dari bubuk silika memiliki nilai $0,002 \mathrm{~W} / \mathrm{m} .{ }^{\circ} \mathrm{C}$ di bawah vakum dan mencapai nilai $0,027 \mathrm{~W} / \mathrm{m} .{ }^{\circ} \mathrm{C}$ pada suhu kamar.

Konduktivitas termal batuan sangat ditentukan oleh kandungan mineral yang terdapat di dalam batuan seperti mineral silika. Mineral ini merupakan bahan semikonduktor yang akan berubah menjadi konduktor ketika berada pada suhu tinggi. Mineral silika pada sumber mata air panas ditemukan dalam bentuk batu kuarsa (DiPippo, 2012). Horrai (1969) mendapatkan bahwa mineral yang memiliki fasa kuarsa maka akan memiliki ukuran yang kecil sehingga nilai konduktivitas termalnya akan bernilai lebih tinggi. Endovani dan Putra (2015) mendapatkan 
kandungan silika pada batuan endapan sinter silika di Sapan Maluluang menggunakan XRF itu sebesar $87,42 \%$. Kandungan silika yang sebesar ini menyebabkan nilai konduktivitas termal endapan sinter silika di Sapan Maluluang memiliki nilai yang tinggi.

Tingginya nilai konduktivitas termal endapan sinter silika juga dipengaruhi oleh porositas, dan densitas. Untuk batuan yang mempunyai jarak antar kisi penyusunnya kecil (rapat) dengan sedikit rongga (massive) dan densitas yang besar, maka cenderung mempunyai nilai konduktivitas panas yang besar (Sulistiyo, 2002). Nilai konduktivitas termal endapan sinter silika di mata air panas Sapan Maluluang, Kabupaten Solok Selatan memiliki nilai yang tinggi. Hal ini disebabkan karena memiliki porositas yang kecil yaitu sebesar 9,12 \% (Endhovani dan Putra, 2015).

\subsection{Uji Konduktivitas Termal Endapan Sinter di Kabupaten Solok}

Nilai konduktivitas termal endapan sinter di mata air panas di Garara dan Cupak, Kabupaten Solok memiliki nilai rata-rata $21,75 \mathrm{~W} / \mathrm{m}^{\circ} \mathrm{C}$. Nilai rata-rata konduktivitas termal endapan sinter tiap titik dapat dilihat pada Tabel 2. Berdasarkan penelitian sebelumnya yang dilakukan oleh Inanda (2017) mendapatkan bahwa di mata air panas Garara Kabupaten Solok memiliki endapan sinter silika, sedangkan di mata air panas Cupak Kabupaten Solok memiliki endapan sinter karbonat (Burhan, 2017). Endapan sinter di Kabupaten Solok memiliki dua jenis endapan sinter yaitu sinter silika dan karbonat dengan persentase yang berbeda. Nilai konduktivitas termal rata-rata endapan sinter silika yang didapatkan di mata air panas Garara berkisar antara $21,18-21,94 \mathrm{~W} / \mathrm{m} .{ }^{\circ} \mathrm{C}$. Nilai konduktivitas termal endapan sinter karbonat yang didapatkan di mata air panas Cupak berkisar antara 19,20-23,41 W/m. ${ }^{\circ} \mathrm{C}$. Perbedaan nilai konduktivitas termal sampel endapan sinter di mata air panas Cupak dan Garara ini, disebabkan karena perbedaan dari karakterisitik dan kandungan mineral sampel yang diambil pada masingmasing lokasi pengambilan sampel. Menurut Pasquale (2015), nilai konduktivitas panas dari batuan karbonat memilki nilai 2,95-3,36 W/m. ${ }^{\circ} \mathrm{C}$.

Tabel 2 Nilai rata-rata konduktivitas termal endapan sinter tiap titik

\begin{tabular}{|c|c|c|c|c|}
\hline No & Lokasi & Sampel & $\lambda\left(\mathbf{W} / \mathbf{m} .{ }^{\circ} \mathbf{C}\right)$ & Rata-rata $\left(\mathrm{W} / \mathrm{m} .{ }^{\circ} \mathrm{C}\right)$ \\
\hline 1 & \multirow{3}{*}{ Garara I } & $2 \mathrm{~A}$ & 24,93 & \multirow{3}{*}{21,94} \\
\hline 2 & & $2 \mathrm{~B}$ & 18,63 & \\
\hline 3 & & $2 \mathrm{C}$ & 22,26 & \\
\hline 4 & \multirow{3}{*}{ Garara II } & $3 \mathrm{~A}$ & 21,45 & \multirow{3}{*}{21,18} \\
\hline 5 & & $3 \mathrm{~B}$ & 20,88 & \\
\hline 6 & & $3 \mathrm{C}$ & 21,21 & \\
\hline 7 & \multirow{3}{*}{ Cupak I } & $4 \mathrm{~A}$ & 22,36 & \multirow{3}{*}{23,05} \\
\hline 8 & & $4 \mathrm{~B}$ & 24,80 & \\
\hline 9 & & $4 \mathrm{C}$ & 22,00 & \\
\hline 10 & \multirow{3}{*}{ Cupak II } & $5 \mathrm{~A}$ & 21,35 & \multirow{3}{*}{19,20} \\
\hline 11 & & $5 \mathrm{~B}$ & 16,85 & \\
\hline 12 & & $5 \mathrm{C}$ & 19,41 & \\
\hline 13 & \multirow{3}{*}{ Cupak III } & $6 \mathrm{~A}$ & 23,83 & \multirow{3}{*}{23,41} \\
\hline 14 & & $6 \mathrm{~B}$ & 25,06 & \\
\hline 15 & & $6 \mathrm{C}$ & 21,35 & \\
\hline & & Rata-rata & & 21,75 \\
\hline
\end{tabular}

Pada masing-masing lokasi penelitian, didapatkan konduktivitas termal endapan sinter karbonat maupun endapan sinter silika dari ketiga titik pengambilan sampel yang tidak jauh berbeda. Hal ini mengindikasikan bahwa ketiga sampel endapan sinter karbonat maupun sinter silika diambil di setiap lokasi penelitian berasal dari satu sumber yang sama. Endapan sinter yang berasal dari satu sumber akan memiliki jenis dan jumlah kandungan mineral yang sama, sehingga besaran fisis yang dihasilkannya juga tidak jauh berbeda.

Konduktivitas termal batuan sangat ditentukan oleh kandungan dari mineral yang terdapat pada batuan. Mata air panas Cupak I memiliki nilai konduktivitas termal endapan sinter 
yang lebih tinggi dibandingkan dengan mata air panas Cupak II. Hal ini disebabkan karena pada masing-masing mata air panas memiliki kandungan mineral karbonat yang berbeda. Berdasarkan penelitian yang dilakukan oleh Burhan dan Putra (2017) yang mendapatkan bahwa kandungan mineral karbonat pada mata air panas Cupak I yaitu 481,66 ppm sedangkan daerah Cupak II hanya memiliki kandungan mineral karbonat yaitu 378,33 ppm. Semakin besar kandungan mineral karbonat dalam endapan sinter maka nilai konduktivitas termal juga semakin besar.

Nilai konduktivitas termal endapan sinter pada mata air panas Garara lebih rendah dibandingkan dengan nilai konduktivitas termal endapan sinter pada mata air panas Cupak. Mata air panas Garara memiliki kandungan mineral silika yang tidak terlalu dominan, dimana kandungan mineral silika pada endapan sinter di mata air panas Garara bernilai 54,28 \% dan kandungan karbonatnya hanya bernilai 3,33 \% (Dona dan Putra, 2016). Semakin besar kandungan silika dalam endapan sinter maka nilai konduktivitas termal juga semakin besar.

Perbedaan kandungan mineral juga disebabkan karena perbedaan karakteristik batuan reservoir tempat terbentuknya air panas di bawah permukaan bumi. Perbedaan karakteristik batuan reservoir seperti temperatur mengakibatkan perbedaan jenis mineral yang terlarut dan terbawa oleh fluida sampai ke permukaan bumi. Temperatur yang sudah menurun menyebabkan terbentuknya endapan sinter di permukaan bumi (Rimstidt dan Cole, 1982).

\subsection{Hubungan antara Nilai Konduktivitas Termal dengan Jenis Endapan Sinter}

Berdasarkan Tabel 3, nilai konduktivitas termal endapan sinter tertinggi terdapat di mata air panas Sapan Maluluang, Kabupaten Solok Selatan. Hal ini disebabkan karena di mata air panas Sapan Maluluang memiliki kandungan mineral silika yang cukup tinggi yaitu sebesar 87,42 \% sedangkan kandungan mineral karbonatnya hanya sebesar 0,74 \% (Endovani, 2016). Nilai konduktivitas termal yang terdapat di mata air panas Cupak relatif konstan disebabkan karena daerah tersebut memiliki kandungan mineral karbonat yang tidak terlalu jauh berbeda. Mata air panas Garara memiliki nilai konduktivitas termal endapan sinter yang lebih rendah jika dibandingkan dengan mata air panas Cupak dan Sapan Maluluang, meskipun mata air panas Garara ini hanya memiliki kandungan silika sebesar 54,28 \% yang bernilai lebih kecil dibandingkan dengan kandungan mineral silika di mata air panas Sapan Maluluang (Dona, 2016). Perbedaan nilai konduktivitas termal endapan sinter juga dipengaruhi oleh suhu kamar. Pengukuran konduktivitas termal ini dilakukan pada suhu rata-rata yaitu $25,7^{\circ} \mathrm{C}$. Tinggi rendahnya suhu kamar akan menghasilkan pergeseran nilai konduktivitas termal pada saat pengukuran.

Tabel 3 Nilai rata-rata konduktivitas termal dan jenis endapan sinter

\begin{tabular}{clccc}
\hline No. & Lokasi & $\begin{array}{c}\text { Jenis } \\
\text { Endapan } \\
\text { Sinter }\end{array}$ & Kandungan & $\begin{array}{c}\text { Nilai Rata-rata } \\
\text { Konduktivitas Termal } \\
\left.\text { (W/m. }{ }^{\mathbf{0}} \mathbf{C}\right)\end{array}$ \\
\hline 1. & $\begin{array}{l}\text { Sapan } \\
\text { Maluluang }\end{array}$ & Silika & $\begin{array}{c}\text { Silika 87,42 \%, } \\
\text { karbonat 0,74 \% }\end{array}$ & 26,49 \\
\hline 2. & Garara I & Silika & $\begin{array}{c}\text { Silika 54,28 \%, } \\
\text { karbonat 3,33 \% }\end{array}$ & 21,94 \\
\hline 3. & Garara II & Silika & - & 21,18 \\
\hline 4. & Cupak I & Karbonat & Karbonat 481,66 ppm & 23,05 \\
\hline 5. & Cupak II & Karbonat & Karbonat 378,33 ppm & 19,20 \\
\hline 6. & Cupak III & Karbonat & - & 23,41 \\
\hline
\end{tabular}

(Sumber kandungan: Burhan dan Putra, 2017; Endhovani dan Putra, 2015; Dona dan Putra, 2016)

Konduktivitas termal batuan mengindikasikan seberapa cepat panas dalam reservoir mengalir sampai ke permukaan bumi. Semakin ke dalam bumi, batuan akan memiliki susunan yang kompak dan panas bumi yang semakin tinggi. Hubungan konduktivitas termal dengan panas bumi adalah semakin tinggi panas dalam bumi maka akan menghasilkan nilai konduktivitas panas batuan yang semakin tinggi (Basid, 2014). 
Menurut Pasquale (2015), batuan karbonat memiliki porositas yang lebih tinggi dibandingkan dengan batuan silika, sehingga menyebabkan nilai konduktivitas termal batuan silika lebih tinggi dibandingkan dengan batuan karbonat. Oleh karena itu, dapat disimpulkan bahwa daerah Sapan Maluluang mempunyai potensi panas bumi yang lebih baik daripada di daerah Cupak dan Garara Kabupaten Solok.

\section{KESIMPULAN}

Nilai konduktivitas termal endapan sinter silika di mata air panas Sapan Maluluang, Kabupaten Solok Selatan memiliki nilai rata-rata sebesar $26,49 \mathrm{~W} / \mathrm{m}^{\circ} \mathrm{C}$, sedangkan nilai konduktivitas termal endapan sinter di mata air panas Garara dan Cupak, Kabupaten Solok memiliki nilai rata-rata $21,75 \mathrm{~W} / \mathrm{m}^{\circ} \mathrm{C}$. Tingginya kandungan silika dan karbonat akan menghasilkan nilai konduktivitas termal yang lebih tinggi. Nilai konduktivitas termal endapan sinter tertinggi terdapat di mata air panas Sapan Maluluang Kabupaten Solok Selatan. Berdasarkan nilai konduktivitas termal endapan sinter dapat disimpukan bahwa daerah Sapan Maluluang mempunyai potensi panas bumi yang lebih baik daripada di daerah Kabupaten Solok.

\section{DAFTAR PUSTAKA}

Basid, A., Andrini, N., dan Arfiyaningsih, S.,"Pendugaan Reservoir Sistem Panas Bumi Dengan Menggunakan Survey Geolistrik, Resistivitas Dan Self Potensial", Jurnal Neutrino,7, 57-70, (2014).

Burhan, D. dan Putra, A.,"Pemetaan Tipe Mata Air Panas di Sumatera Barat", Prosiding Seminar Nasinal Fisika Universitas Andalas 2017, (Universitas Andalas, Padang, 2017).

DiPippo, R., "Geothermal Power Plants: Principles, Applications, Case Studies and Enviromental Impact", Elsevier Ltd (United Kingdom, 2012).

Dona, M.R. dan Putra, A., "Estimasi Temperatur Reservoir Panas Bumi dengan Metode Resistivitas Probe Dua Elektroda, Jurnal Fisika Unand, 5, 199-204 (2016).

Endhovani, R. dan Putra, A., "Analisis Konduktivitas Termal dan Porositas Sinter Silika Sumber Mata Air Panas di Sapan Maluluang Kecamatan Alam Pauh Duo Kabupaten Solok Selatan”, Jurnal Fisika Unand , 5, 65-72 (2015).

Horrai, K. dan Simmons, G., 1969, "Thermal Conductivity Of Rock-Forming Minerals", Earth And Planetary Science Letters, 6, 359-368 (1969).

Hochstein, M. P. dan Browne, P. R. L., "Surface Manifestation of Geothermal System With Volcanic Heat Sources", Academic Press (San Diego, 2000).

Inanda, Y.D. dan Putra, A.,"Karakteristik Sinter Silika pada Mata Air Panas di Kabupaten Solok Selatan dan Kabupaten Solok", Prosiding Seminar Nasinal Fisika Universitas Andalas 2017, (Universitas Andalas, Padang, 2017).

Nugroho, B. E, dan Putra, A., "Estimasi Temperatur Reservoir Panas Bumi Berdasarkan Resistivitas Listrik Teras Silika di Sekitar Mata Air Panas Kecamatan Alam Pauh Duo Kabupaten Solok Selatan", Jurnal Fisika Unand, 4, 339$343(2015)$

Pasquale, V., Verdoya, M., dan Chiozzi, P., "Measurements of Rock Thermal Conductivity with a Transient Divided Bar", Elsevier, 53, 183-189 (2015).

Rachmawati, D.A., "Sintesa Isolator Panas Nano Porous Silika dari Water Glass dengan Metode Deposisi Elektroforesis", Skripsi S1, ITS, 2013.

Rimstidt, J., D. dan Cole, D., R., "The Mechanism of Formation of The Beowawe, Nevada Siliceous Sinter Deposit", Geothermal Mineralization I (Division of Geothermal Energy, Nevada, 1982)

Saptadji, N. M., "Teknik Panas Bumi”, Institut Teknologi Bandung (Bandung, 2009).

Sipio, D.E., Chiesa, S., Destro, E., Galgaro, A., Giaretta, A., Gola, G., Manzella, A., 2013, "Rock Thermal Conductivity as Key Parameter for Geothermal Numerical Models", Elsevier, 40, 87-94 (2013). 
Sulistyo, "Penerapan Hukum Fourier untuk Menetukan Konduktivitas Panas Batuan", Skripsi S1, UNDIP, 2002.

Velez, I.M., Blessent, D., Cordoba, S., Sanchez, L.J., Raymond, J., Palacio, P.E., "Geothermal Potential Assessment of Nevado Del Ruiz Volcano based on Rock Thermal Conductivity Measurements and Numerical Modelling of Heat Transfer", Journal of South American Earth Sciences, 10, 1-33 (2017).

Wohletz, K, dan Heiken, G., "Volcanology and Geothermal Energy Press", Brekele (University of California, United States of America, 1992). 